\title{
MOBILE APPLICATIONS AND YOUTH INVOLVEMENT IN FARMING
}

\author{
Aigul Meirmanova \\ Enterprise Theory and Practice Doctoral School, University of Miskolc, Miskolc, Hungary \\ aygulmeyr@mail.ru
}

Abstract: According to the UN forecasts, by 2020 the world population will be over 9 billion people, to feed this huge amount of people the food production should grow by $70 \%$. It means that the number of farmers, who are the main suppliers in food production, should be increased. How to enlarge the number of rural farmers? By getting young people interested in farming and agriculture. But nowadays young people are prone to move to big cities. Why young people are not involved in agriculture, what initiatives are being taken to support youth in agriculture and what recommendations can be given, so that young people stay in it? Using the potential and energy of youth in agriculture, comprehensive and integrated policies, programs for markets and trade should be available with special attention to promotions and conditions for young people, who are going to be farmers. In this paper we propose mAgriculture tools such as mobile phones and its applications from throughout the world as an instrument to draw attention of young people to agriculture, showing useful and best examples how farmers could increase their profit and yield through them. These applications help to display information about current prices of agricultural products, historical charts and future prices, comparing the prices of products at different intervals, helps to find significant trends and correlations, also farmers receive information on contracts and the latest news from the agricultural area etc.

Keywords: growth, innovation, farmers, technological change, economic development, yield.

JEL classification: 03.

\section{Background}

By 2030 , nearly $60 \%$ of the world's population will live in urban areas, which will transform the shape of consumer demand and increasing pressure on land and other resources (FAO, 2017). The proof for this statement is shown in the figure below, where we can see that in 2030 the urban population will be five billion people in the world:

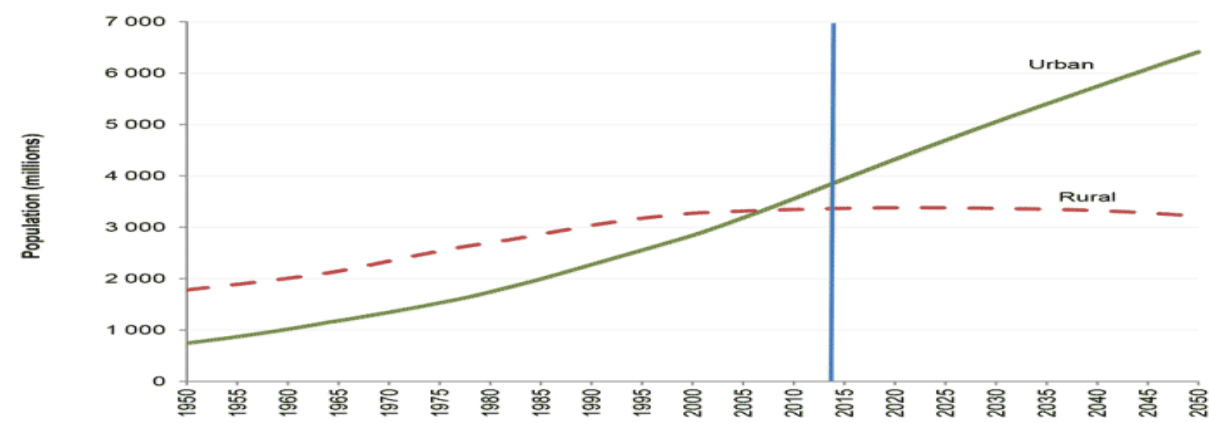

Figure 1: The ratio of urban and rural populations around the world Source: World Urbanization Prospects: The 2014 Revision 
In other words, the entire expected population growth - from 7 billion to 10 billion - will be associated with the growth of the urban population and a stable decreasing number of the rural population. The overwhelming majority of immigrants are young people aged 15-35 years. Such age qualification is due to the fact that people of more solid age prefer to stay in rural areas where they were able to arrange and are afraid to change something in life, valuing the acquired social status. Why do young people immigrate to big cities? Sociologists call the search for a better life is the main reason for urbanization. Indeed, with each new generation, life in rural areas become less and less profitable, especially against the background of the lifestyle of citizens who are not burdened with heavy physical labor. What should be done to make it interesting for them to live and work in the countryside? What will be the situation in 2050 when the demand for food is projected to be $70 \%$ higher? Motivation is a stimulus that produces action and directed action is a primary function of management (Barnard et al., 2013). Atkinson et al. (1978) referred motivational factors as one of the important determinant of aspirations and further added that a person with motive of success have higher aspirations than the person with motive to avoid failure. As shown in the figure below, what can be a bold motivation for decreasing number of young people which growing at a geometric rate in agriculture to stay in rural places and be involved in agriculture around the world?

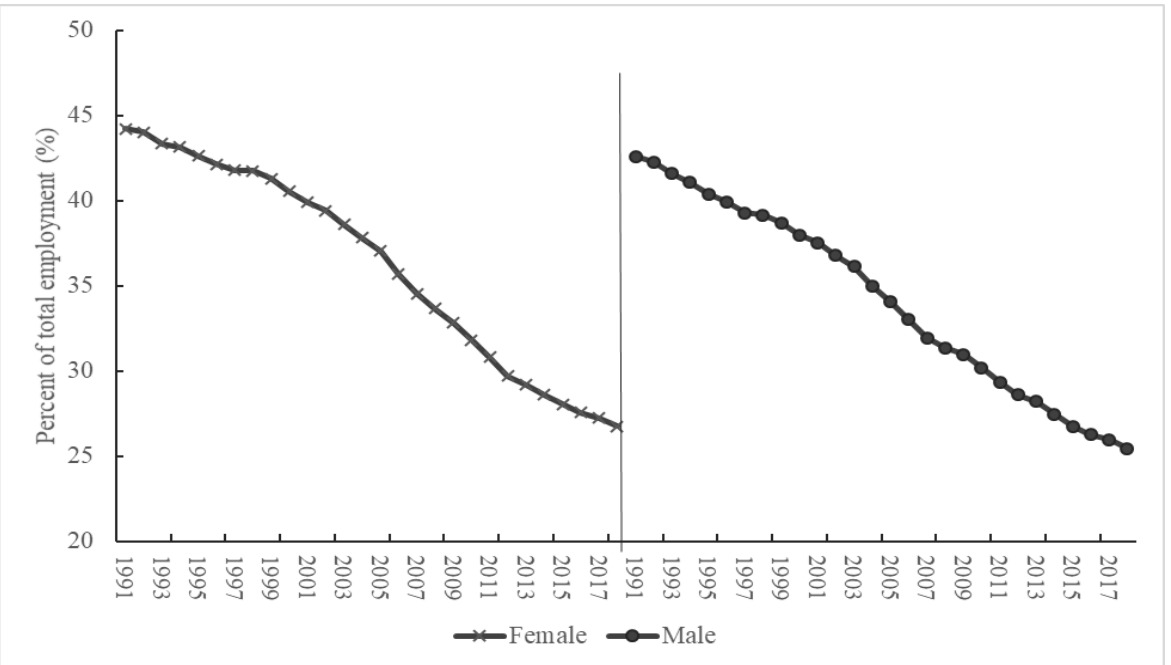

Figure 2: Youth involvement in agriculture in the world (1991-2017)

Source: Worldbank.org (2018) World Population Prospects

One of the answers is mAgriculture, which is a subset of eAgriculture, referring to the delivery of agriculture-related services via mobile communications technology (Brugger, 2011). Mobile communication technology includes all kinds of portable devices like basic mobile phones, smartphones or tablet devices and etc. In many countries, there is a projected shortage of skilled young workers. Despite the fact that young people are often considered as "digital natives" and the most of them has access to the Internet and mobile devices, however many of them do not have the necessary digital skills to work in a particular sectors of the economy (Theguardian, 2014). Governments, social partners, private sector, academia, civil society and other key stakeholders should ensure that young people can improve their digital skills so that they need to take advantage of employment or business opportunities and build an open digital economy and society. Young people with advanced digital skills have the opportunities to earn more and contribute to the prosperity of the digital economy. Digital skills are increasingly needed in various workplaces around the 
world, because information communication technologies are rapidly transforming jobs in various sectors, including agriculture, the entertainment industry, financial services, health care and transport etc.

\section{Usefulness of mobile applications in agriculture and its positive effect on yield and income of farmers}

Mobile phones can provide better access to farmer advisory services directly on-farm and facilitate information sharing on a large scale, improve farmer's decision-making processes (Payene and McCarthy, 2010). Nowadays, more and more farmers on their gadgets running Android or iOS are installing specialized applications that focus on the agricultural industry. Positive correlation revealed between the benefits of mobile applications (but not implementation level) with the material wealth and education level of farmers. As in the case of specific technologies (e.g use of high-yielding seeds), probably the use of mobile applications will bring great benefits to farmers with a higher level of education and the best material wealth (Cole and Fernando, 2012). Let's monitor some useful applications around the world. Such as,

1) Agrowdata (USA). This mobile application displays information about current prices for agricultural products. The application has an user-friendly interface that can demonstrate historical charts and future prices of products. Comparing the prices of products at different intervals helps farmers to find significant trends and correlations.

2) Agrivi (Europe) is one of the most successful startups in Europe. This platform was created to manage modern vertically integrated agriculture. Using Agrivi applications, farmers can monitor product quality, track all work, and also follow generally accepted standards and the owner of any agribusiness can get both a complete and simplified aggregate analysis of the activities of his enterprise. The software package consists of applications that are suitable for both small farms and cooperatives, and even large agro-industrial enterprises.

3) Cocoalink (Ghana) connects cocoa farmers with information about good farming practices. Evoucher (Zimbabwe) helps cash strapped small scale farmers' access agricultural inputs.

4) Green Way (Myanmar) application is one of the one game-changer among agricultural apps which was launched in 2016. The platform provides farmers with up-to-date information on everything from weather and climate change to crop prices and advice on pesticides, fertilisers.

5) The Agronomist's Diary (Russia) is a simple and convenient application for keeping an electronic book on the history of crop rotation fields. It can work with an electronic map of the fields, keep a history of the location of crops, a diary of technological operations and see the consumption of materials in each field, the farmer can save time on the exchange of information between company employees working in the fields and in the office.

ICTs also have a noticeably positive effect on income growth in developing and developed countries (Roller and Waverman, 2001; Waverman et al., 2005). Mobile phones are being used to help raise farmers' incomes, making agricultural marketing more efficient, lowering information costs, reducing transport costs, and providing a platform to deliver services and innovate (Kevin, 2011; Sife et al., 2010; Donner, 2007).

According to research conducted by Oracle, $32 \%$ of the representatives of the new generation said that in the successful implementation of tasks are helped by "working applications". Today, our mobile devices are not different from a PC. They have all the same familiar applications to PC. A personal computer is simply more powerful, its screen is larger 
and the keyboard is more convenient. But after 5-10 years, coming home or to the office, smartphones will be connected to the big screen, and this design will replace familiar computer. That is, mobile devices will not be complementary, but the backbone of society. A good example can be given by Daniel Nshimiyimana, who is a tech-savvy Rwandan young farmer who turned his grandparents' godforsaken land into a thriving farm producing bananas. "The mobile applications help by telling me about the quality of seeds I have to plant, the quantity of fertiliser to use the distance between the trees. One bunch of (my) bananas used to weigh 30 kilos. Now they are 40, 50 kilos," Nshimiyimana said proudly, pointing at the trees planted on his farm (Win, 2018). There are a bunch of examples when farmers receive positive effect on yield and income using mobile applications in their farms. The two examples (Mexico and Kenya) can be raised up below regarding the usefulness of the mobile applications.

First, Rezatec, a leading provider of geospatial data analytics to the Infrastructure, Forestry and Agribusiness sectors in the world, has launched a new mobile application aimed at helping Mexican farmers improve crop (wheat and sugar) productivity and stabilise their incomes to facilitate rural community economic development. Wheat farming in the Yaqui Valley in Mexico is at the forefront of cutting edge technologies for wheat compared to other parts of the developing world. Average wheat yields are currently around 6.2 tonnes per hectare, with considerable variability every year (Haskell, 2018). Annual profits from wheat production in the Yaqui Valley varied by $60 \%$ per tonne from 2009 to 2017, with a steady rise in the total cost of production over time. Better management practices by smallholder farmers for nitrogen application, irrigation and weeds would help to improve yields and productivity (Haskell, 2018). The sugarcane industry also currently generates more than 930,000 direct jobs and employs another 2.2 million people directly, contributing approximately US $\$ 2.5$ billion per annum to the Mexican economy (Haskell, 2018). The average yield is currently close to 70 tonnes of cane per hectare however smallholder farmers have below average productivity partly because they have not adopted modern methods of agriculture. Second, ICow, the best mobile application in Africa, is intended to remedy the plight of Kenyan farmers. More than 20,000 dairy producers use information services to efficiently and economically manage their farms, reducing operating expenses and increasing profits by twice. ICow application concluded that the majority of dairy farmers receive only a small part of the possible income because they use outdated methods and inefficiently manage their farms. Technologies are developing by leaps and bounds, Africa is the second largest region in terms of subscribers after Asia. Despite the fact that in many places there is not even light, every fourth Kenyan uses mobile services. Therefore, should not occur.

\section{Significance and importance of mAgriculture tools and its impact on getting young generation interested in farming}

In agriculture, as in other areas of the economy, the innovation process is characterized by consistency, cyclical nature, probability, social and environmental importance. Innovation, according to many academic economists and others, is the end result of the innovation process and finds expression in the form of a new or improved product or technology that is marketed and used in practical activities. Several studies (Selassie, 2001; Oladele, 2006; Adesope et al., 2007; Salau et al., 2008) have pinpointed the importance of information in agricultural development and its potential in improving the effectiveness of rural development in general.

May et al. (2007) and Yekini et al. (2012) also identified that ICT had the potential to reduce poverty and improve livelihoods by empowering users with timely information and knowledge, reducing transaction costs, and appropriate skills for increasing productivity. 
Table 1: mAgriculture services and projects around the world

Internet platforms: many governments and research institutions offer or work towards comprehensive internet platforms that provide access to all relevant information.

\begin{tabular}{l|l|}
$\begin{array}{l}\text { Philippines: } \\
\text { e-extension }\end{array}$ & $\begin{array}{l}\text { Government-operated platform that provides comprehensive } \\
\text { information. The innovative features are online training courses on } \\
\text { a broad range of different topics. }\end{array}$ \\
\hline India: Agropedia & Agropedia also offers a crop-specific library, blog and chat. \\
\hline $\begin{array}{l}\text { Pakistan: } \\
\text { Pakissanvii }\end{array}$ & $\begin{array}{l}\text { Pakissan.com is the first and largest agricultural web portal in } \\
\text { Pakistan, providing a platform where the entire agri-community can } \\
\text { connect with each other, sharing ideas, experiences and } \\
\text { information. }\end{array}$
\end{tabular}

Call center approach: on their mobiles, farmers can call a tele-center where agents usually agronomists - answer their questions and provide vital information on cultivation techniques such as planting, irrigation, disease treatment and other input-related issues. The agents also answer queries relating to poultry, livestock and fisheries.

\begin{tabular}{|l|l|}
\hline $\begin{array}{l}\text { Bangladesh: } \\
\text { Jigyasha 7676 }\end{array}$ & $\begin{array}{l}\text { Launched by the second biggest mobile operator Banglalink in } \\
\text { December 2008 as the first mobile-based agro-info service in } \\
\text { Bangladesh. }\end{array}$ \\
\hline $\begin{array}{l}\text { Kenya: Kenya } \\
\text { Farmers' Helpline - } \\
\text { m-Kilimo }\end{array}$ & $\begin{array}{l}\text { KFHL started in September 2009 and provides agricultural and } \\
\text { horticultural information, advice and support. The service primarily } \\
\text { targets individual farmers and will also be accessible to agriculture } \\
\text { extension facilities. }\end{array}$ \\
\hline
\end{tabular}

SMS and voice message delivery (push and pull).

Thailand: *1677 $\quad$ Subscribers receive free information on market trends, commercial Farmer Information crops (rice, vegetable and fruit), livestock and fisheries, important Highway

Nokia Life Tools $\quad$ Launched in India in 2008, Indonesia and China in 2009. Information related to commodity prices, commodity news, agri-inputs prices, weather forecasts and agricultural tips \& techniques.

Uganda: Farmer's

Friend

Farmers can search for agricultural tips through an SMS-based database, covering crop and livestock, pest and disease control information, planting, storage and harvesting tips, as well as regional weather forecasts.

Chile: Mobile Information Project (MIP) / DatAgro Mexico: DigitallCS / It was developed together with a Mexican coffee cooperative to CAMRANDI monitor compliance with fair trade requirements. The application prompts inspectors through every step of the survey process, with both text and audio. The latter option compensates for the small screen on the phone, and helps farmers with literacy problems to follow the process.

Source: Mobile applications in agriculture. Fritz Brugger, 2011

A combination of mAgriculture services and projects from Asian, African and Latin American countries are represented in the figure above due to an increasing number of population and need on food in these continents. The functional essence of the development of innovation is to eliminate the difference between the state of the latest scientific, technical knowledge and production practices. Adoption of innovation contributes: 
- the intellectualization of labor in agricultural production, increasing their knowledge-intensiveness;

- $\quad$ achieving a high technological level of production;

- $\quad$ expanding the range, improving the quality and competitiveness of products;

- efficient use of all types of resources;

- improving working conditions;

- reduce environmental pollution;

- impact on the structure of reproduction in agriculture in accordance with the changing needs and the external environment.

Nowadays the mobile phones as one of the mAgriculture tools has become a symbol of prestige, social positions and fashion trends. The latest mobile phone model has certainly impressed others, especially young people. And why we can not getting interested young people in farming with what they are so impressed?

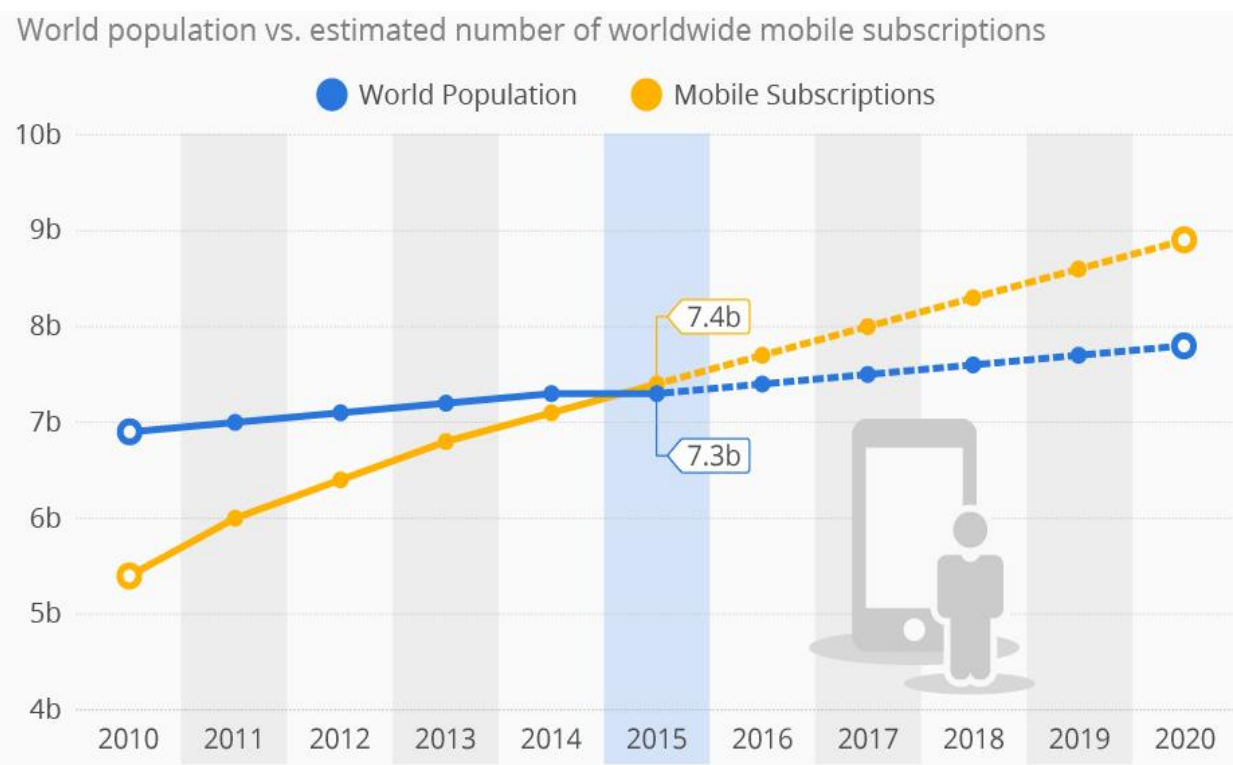

Figure 3: Mobile subcriptions to outnumber the World's Population

Source: Ericsson. United Nations

From the figure above, we can draw the following conclusion: in near future mostly all of us will be an active and modern users of more than one mobile devices. Advantages of mobile devices in agriculture are huge (FAO, 2011):

1. It will help to be in touch: among other things, the main advantage of mobile phones is that the farmers can always contact extension workers anytime wherever they are.

2. It will help to improve the farm's performance: a mobile phone will become an indispensable assistant in farmer's business. With it, they will constantly be in touch with employees and will be aware of their activities in their absence.

3. Simple accessible navigation system: the latest models have a navigation function and a GPRS system. If a mobile phone is equipped with a navigation system, it gives them an opportunity to receive information about its location.

4. Data transfer: modern mobile phones are created using Infrared technology and Bluetooth which allows users to exchange information in seconds. 
5. Modern mobile phones are equivalent to minicomputers. Phones have access to the global Internet and telephones are adapted for different operational systems such as Windows etc.

\section{Conclusion}

On the threshold of the 21st century, the most important key condition for accelerated progress in socio-economic development is an effective innovation policy - an activity whose ultimate goal is to introduce new, advanced equipment and technologies, forms of labor and management organizations based on the achievements of scientific and technological progress. The dynamic social and economic development of many countries in the world should be based exclusively on innovations, the consequences of which have become strategically important. Due to increasing number of young people and their obsession with the devices, such as mobile phones, we can draw their attention to the agricultural sector. They may enlarge the number of small-scale, middle-sized and large farmers, who are ready to help with the food production, which growing exponentially in the world. From aforementioned study we discovered several types of mobile applications throughout the world in Asia, Europe, Africa and the USA. These applications vary from each other in different parameters: quickly and accurately calculate the amount of medications required for the preparation of plant and meat products; offer owners of agribusinesses to discover new methods of growing crops and highly efficient methods of harvesting; provide techniques for controlling all pests, including insects and weeds; the utilities which able to accurately identify various plant and animal diseases, etc. Attracting youth to agriculture is crucially important in all countries around the world - labor resources in agriculture are aging, all fewer people go to work in this sector. According to the Food and Agriculture organization, there are very few young specialists in the agricultural sector, especially in Europe: in 2013 from 10.8 million farm managers only $6 \%$ were younger 35 years. A survey of farmers conducted by Eurostat, showed that more than half EU farm managers reached age 55 years and older. We should take into consideration these simple and cheap applications in helping to engage the younger generation in agriculture before switching to robots, artificial intelligence and machine learning. In order to raise the motivational level of youth to stay in countrysides and be involved in farming, we can use a few methods, for example: motivational trainings, young farmers forums, internships, field trips, dual trainings, etc. In addition, many organizations can be involved directly in the implemention of motivational tools, the only question is literacy and systematic work of staff services. In conclusion, it is worth noting that if the objective parameters of the external environment not conducive to motivation for agricultural occupations, effectively implementing these tools will be problematic. So, while the highest growth rate will demonstrate average wages in the "finance" and "public administration" is not possible speaking about any significant motivation for young people of their involvement in the agricluture. Digital technologies has already become part of our lives. New ideas and startups from our youth, as well as from organizations, universities and companies around the world will help unlock the potential of food and agriculture to reduce poverty, as well as to empower young people and ensure equal opportunities to obtain information, technology and markets. Today our common task is to provide the new generation with the most intuitive and problem free user experience in farming sector. Indeed, despite the general idea that young people can make any kind of work, Generations $\mathrm{X}$ and $\mathrm{Y}$ also prefer to avoid inconvenience in their lives at all costs. 


\section{Acknowledgement}

This article is based on a contribution presented at the 9th edition of the International Conference of Doctoral Students and Young Researchers "Emerging Markets Economics and Business", Oradea, 21.11.2018, and represents an extended version of it.

\section{References}

Atkison, J.W. and Birch, D., 1978. An Introduction to motivation. $2^{\text {nd }}$ Ed., New York: Van Nostrand.

Adesope, O. M., Asiabaka, C. C. and Agumagu, A. C., 2007. Effect of personal characteristics of extension managers and supervisors on information technology needs in the Niger Delta area of Nigeria. International Journal of Education and Development Using Information and Communication Technology, 3(2), pp. 4-15.

Barnard, F., Akridge, J., Dooley, F., Foltz, J., 2012. Agribusiness management. $4^{\text {th }}$ Ed., New York: Routledge.

Brugger, F., 2011. Mobile Applications in Agriculture [online] Available at: https://www.gsma.com/mobilefordevelopment/wpcontent/uploads/2011/12/Syngenta R eport on mAgriculture abridged web version.pdf, [accessed 15.01.2011].

Cole, S. A., and Fernando, N. A., 2012. The Value of Advice: Evidence from Mobile Phone-Based Agricultural Extension. Harvard Business School Working Paper [online] 13-047, Available at: http://nrs.harvard.edu/urn-3:HUL.InstRepos:10007889, [accessed November 2012].

Donner, J., 2007. The Use of Mobile Phones by Microentrepreneurs in Kigali, Rwanda: Changes to Social and Business Networks. Information Technologies and International Development, 3(2), pp. 3-19.

Food and agriculture organization, 2017. Rural areas, too long seen as poverty traps, key to economic growth in developing countries? [online] Available at http://www.fao.org/news/story/en/item/1042091/icode/ [accessed 9.10.2017].

Food and agriculture organization, 2011. Mobile telephony in rural areas [online] Available at: http://www.fao.org/3/ap738e/ap738e.pdf [accessed 01.02.2019].

Haskell, S., 2018. Mobile app helping Mexican farmers improve sugar cane and wheat yield through the analysis of satellite data [online] Available at https://www.rezatec.com/mobile-app-helping-mexican-farmers-improve-sugar-cane-an d-wheat-yield-through-the-analysis-of-satellite-data/ [accessed 14.06.2018].

Kevin, D., 2011. Anytime, anywhere: Mobile devices and services and their impact on agriculture and rural development. ICT in Agriculture, pp. 49-70.

May, J., Karugia, J. and Ndokweni, M., 2007. Information Comunication Technologies and Agricultural Development in Sub-Saharan Africa. South Africa, pp. 51.

Oladele, O. I., 2006. Multilinguality of Farm Broadcast and Agricultural Information Access in Nigeria. Nordic Journal of African Studies,15(2), pp. 199-205.

Payene, J. and McCarthy, S., 2010. African Agriculture and ICT: An Overview, USAID Briefing Paper, pp.1-5.

Roller, L. H. and Waverman, L., 2001. Telecommunications Infrastructure and Economic Development: A Simultaneous Approach. American Economic Review, 91(4), pp. 909-923. Sife, S. A., Kiondo, E. and Lyimo-Macha, J. G., 2010. Contribution of Mobile phones to Rural Livelihoods and Poverty Reduction in Morogoro Reion, Tanzania. Electronic Journal on Information Systems in Developing Countries, 42(3), pp. 1-15.

Selassie, S. G., 2001. The Development of Integrated Management Information systems for Agricultural Extension Institutions of Developing Countries: The case of Oromia Agricultural Development Bureau of Ethiopia / Samuel Gebre-Selassie. Aachen: Shaker. 
Salau, E. S. and Saingbe, N. D., 2008. Access and Utilization of Information and Communication Technologies (ICTs) Among Agricultural Researchers and Extension Workers in Selected Institutions in Nasarawa State of Nigeria. Production Agriculture and Technology, 4(2), pp. 1-11.

Theguardian.com, 2014. Young people need to hone their digital skills for futureproof careers [online] Available at

https://www.theguardian.com/careers/young-people-need-hone-digital-skills-futureproof-ca reers [accessed 14.03.2019].

Waverman, L., Meschi, M. and Fuss, M., 2005. The Impact of Telecoms on Economic Growth in Developing Countries. The Vodafone Policy Paper Series, pp. 1-23.

Win, T., 2018. African governments are using technology to get young people interested in farming [online] Available at https://www.weforum.org/agenda/2018/10/africa-bets-on-technology-to-lure-youth-to-farmin $\mathrm{g} /$ [accessed 05.10.2018].

Yekini, N. A., Rufai, M. M., Adetoba, B. T., Akinwole, A. K. and Ojo, O., 2012. ICT Tools for Poverty Eradication and Economic Growth in Nigeria, 2, pp. 13-19.

\section{Bio-note}

Aigul Meirmanova is a PhD student in second year of study at the University of Miskolc (Hungary), Enterprise Theory and Practice Doctoral School and currently she is working on PhD thesis: "An evaluation of factors on technology adoption of farmers in the context of e-agribusiness in Kazakhstan". Her main research fields are: innovation management, knowledge management and economic development (technological change and growth, its consequences and diffusion processes). 